\title{
Libraries in the Digital Age (LIDA) Conferences: A retrospective from the 2000s to the present day
}

\author{
Drahomira Cupar and Tatjana Aparac-Jelušić* \\ Department of Information Sciences, University of Zadar, Zadar, Croatia
}

This special issue of Education for Information (EfI) brings selected papers that were presented at the LIDA 2020 International Conference, held online in 2021 due to the COVID 19 pandemics. The whole process of submitting the papers based on the presentations during the conference was complicated, slowed down and uncertain for several reasons, among them are those which relate to the fact that authors were not sure until the very last moment if the Conference will be held at all.

Before introducing the readers to the content of this issue, let us first present briefly the LIDA Conference and its main goal which is to bring together prominent professors and practitioners and students of library and information science (LIS) academic programs from around the world. Basically, the educational dimension has been a driving force over the years.

Incentives for such a Conference date back to the beginning of 1980s when Information Science in Croatia was developing as a recognised academic and scientific field but lacked competent teachers and leaders. The basic idea was to continue where professor Božo Težak's efforts, pioneer of Information Science in former Yugoslavia and a powerful international relations ambassador of the field, were cut short in 1980s by his death. Some attempts were made to continue to some extent international gatherings every year at the International University Centre in Dubrovnik, but without significant outcomes for a wider LIS audience.

The beginnings of LIDA are connected with professor Tefko Saracevic who recognised the potentials of building a yearly communication platform which will enable students, not only from Croatia, and LIS experts from USA and Europe to learn from each other, to communicate and build future networks. The main paths were agreed upon during the COLIS 3 Conference in Dubrovnik (1999) between Tefko Saracevic, Pertti Vakkari, Peter Ingwersen and Tatjana Aparac-Jelušić and the decision was made: to start the new conference from 2000 onwards. Several promising students

${ }^{*}$ Corresponding author: Tatjana Aparac-Jelušić, Department of Information Sciences, University of Zadar, Zadar, Croatia. E-mail: aparact@gmail.com. 
from the University of Zagreb have been invited to participate in LIDA and over the years they gained confidence and experience in organising such an international conference, and almost all of them later became leading young academicians at the three departments of information sciences in Croatia (universities of Zagreb, Osijek and Zadar). It should be pointed out that Tefko's perseverance and faith in this enthusiastic group of students and teaching assistants was a very strong support during many years until he retired in 2016.

LIDA started modestly as a three-day conference with 9 presentations, 5 workshops, one panel and one virtual tutorial and 56 participants only, including organisers and students. Over the years, its attendance steadily increased. However, it was decided that the conference will not have more than 150 participants as the main aim was to ensure that all participants have a chance to socialise, network and exchange experiences, ask questions, comment, and generally participate actively in discussions, including those that took place during walks in the beautiful landscape of the island of Mljet, in Dubrovnik, Kornati islands and other magnificent places on the Adriatic coast.

When LIDA moved from Dubrovnik to Zadar (2009), it changed its pattern from being held every year to being a biannual conference, mostly because the 'drive' has grown to the point that it took much more time to prepare it, especially taking into account the growing commitments of young information sciences departments following the reorganisation of university programs according to the Bologna model.

Even a cursory glance at the LIDA's topics shows that the educational aspect was and remains the main goal of the conference. Early on, students learned about the positioning of libraries on the Internet and using Internet in libraries; ethics and legal issues and Internet; integrating Information Seeking and Retrieval; WWW and Information Retrieval; WWW and libraries, especially children's libraries; Human Information Behaviour; competencies for Digital Libraries (DL). The experienced professionals discussed with them what digital libraries can do that traditional libraries cannot or what can they do in addition, as well as how to build a small digital library and manage digital library networks.

In the second half of the first decade of the $21^{\text {st }}$ century, the central topics were cultural, social and institutional effects and place of DL; building a DL for children and young adults; users and use of DL; economics of DL; education and training in DL; reference services in digital environments; changes brought by and in DL over 10 years; heritage issues and DL; digital scholarship supported by DL; challenges and innovations in reaching out to digital born generations.

The second decade brought many changes and challenges in the world of library and information services. Therefore the focus of LIDA conference was on issues related to the evolution and innovation in DL and changes in the world of electronic resources; qualitative methods in assessing libraries, users, and use; applications issues; results in altmetrics; digital curation and preservation; use studies; education and training for DL collections. Social justice, community engagement and information institutions were discussed from the point of view of access, diversity, and inclusion. Finally, 
LIDA 2020 focused on the issues related to the reshaping identity in the digital age with a special emphasis on people, libraries, data, technology and ethics.

Over 20 years, LIDA conferences relied on the kindness and high professional motivation of its invited lecturers to whom it owes immense gratitude. At the beginnings, invited lecturers were chosen mostly through collegial connections, and included Tefko Saracevic, Robert Hayes, Rafael Cappuro, Paul Sturges Thomas Froelich, Michael Menou, Maurice Line, and Christine Borgman. They brought not only their knowledge and experience but paved the way for a high standard of presentations and discussions, which has become a brand for future LIDA presenters.

In 2002, it was a special 'treat' to hear about Information Seaking \& Retrieval (IS\&R) research conducted by such great scholars in IS\&R area like Peter Ingwersen, Kalervo Järvelin, Nick Belkin and Carol Kuhlthau, joined by prominent names such as Peiling Wang, Elisabeth Liddy, Collen Cool, David Bowden and Lynn Robinson. Most of them continued to attend LIDA almost regularly whenever their numerous commitments allowed.

At LIDA conference 2003 which was held in beautiful surroundings of a national park on the island of Mljet, a long-lasting collaboration with ASIS\&T started. Starting then, regular events called 'official breakfast with ASIS\&T' with lecturers who were members of ASIS\&T were organised in order to introduce students and teaching assistants to the role of ASIS\&T for their professional development and to assist them when creating their own networks. This is undoubtedly one of the most important outcomes of LIDA for young generations of LIS scholars and professionals, which in several cases resulted with joint research projects and published works as well as with the revival of the European Chapter of ASIS\&T (ASIS\&T/EC). A special credit for the Chapter's revival goes to Emil Levine. Initially the Chapter consisted of members of the newly established student chapter who later continued their work at ASIS\&T/EC. It is necessary to point out that this Chapter has become one of the most active ASIS\&T chapters, winning the title of its best chapter for several years in a row.

The idea to introduce LIDA participants with guests of honour was also deeply embedded in the effort to introduce students and young scholars to the leading experts in the LIS area. The list is really impressive: Maurice Line, Eugene Garfield, Robert Hayes, Jack Meadows, Christine Borgman, Peter Ingwersen, Michael Buckland, Edward Fox, Diane Sonnenwald, Gary Marchionini, Tefko Saracevic, and as a way to say goodbye to the co-organiser, Tatjana Aparac-Jelušić.

For some time, LIDA was perceived as an 'American' conference. This is to a large degree true for its beginning years when the list of lecturers from America was significantly larger than those from Europe. After a few years, as LIDA was accepted in the international and domestic information and library community, and ASIS\&T ranked it among the recommended conferences, the participation of reputed experts from many European countries (Finland, Sweden, Norway, Denmark, Lithuania, Estonia, Latvia, Germany, Czech Republic, Slovakia, England, Scotland, Wales, Ireland, Italy, France, Spain, Austria, Netherlands, Greece, Serbia, Hungary, Russia, 
Bosnia and Herzegovina) as well as from Canada, Australia, South Africa, Korea and Japan, began to increase.

In 2016, Tefko Saracevic and Tatjana Aparac-Jelušić were replaced as co-directors by Ross Todd and Marie Radford from Rutgers University, Martina Dragija Ivanović and Drahomira Cupar from the University of Zadar and Sanjica Faletar Tanacković from the University of Osijek.

The papers presented at the early LIDA conferences were published only for the participants until the decision was made to publish e-proceedings (freely available at the conference website) and to offer some video presentations that are available at https://meduza.carnet.hr/index.php/media/videos?pack=421. For several years LIDA proceedings were published in Libellarium: journal for the research of writing, books, and cultural heritage institutions, an open access Croatian journal (http://www.libellarium.org/index.php/libellarium/issue/view/55).

As mentioned earlier, the editorial idea was to invite all LIDA 2021 participants with accepted papers to upload their works for double-blind review process to be eligible for the publishing in EfI. Some authors decided not to publish their presentations while other authors chose other journals as venues for publication. In this special issue, we have a selection of papers that represent only one part of LIDA's rich and diverse conference program. The main topic of the LIDA 2021 conference was "What is the identity and role of libraries in the digital age?"? Thus, in this issue of EFI we present eight papers that elaborated diverse and highly relevant problems in the wide field of LIS.

Brian Dobreski and Barbara Kwaśnik present their insightful paper on Dimensions of personhood in cultural heritage: Who (or what) gets to be called a person? where they analysed the notion of "person" in cultural heritage institutions. Analysis of ten different definitions in different systems and tools used for organising knowledge revealed five dimensions of personhood: life, actuality, biology, agency, and individuality. Authors speculated on how different conceptualisation of a person should be considered when dealing with "ethical and pragmatic decisions in the emerging issues of identity, including non-human creators, recreated actors, AI agents, and other computational creativity".

In their paper titled Measuring user confidence in social media security and privacy, Mirna Gilman Ranogajec and Boris Badurina researched the degree of students' awareness of the context that influences students' privacy, including their knowledge of privacy policies on social networks, their attitude toward sharing private information on social networks, toward safety and privacy on social media. The study concluded that privacy concern is a subjective attitude that is not related to sharing behaviour and objective understanding of privacy policies but also showed there is a need for raising awareness toward privacy on social media.

Another interesting study is presented in the paper titled Crowdsourcing transcription of historical manuscripts: citizen science as a force of revealing historical evidence from Croatian Glagolitic manuscripts, written by Marijana Tomić, Martina Dragija Ivanović and Laura Grzunov. The paper reports on the pilot study that showed 
possibilities and benefits of citizens' participation in the scholarly projects in humanities, exemplified by the crowdsourcing transcription of manuscripts that present a valuable source for local history written in cursive form of the historical script called Croatian Glagolitic script. The study demonstrated high motivation among students involved in the project as well as of participants in researching their own history through original material and it was shown that there are amateurs who are capable of reading historical script and eager to do it properly when they get an opportunity.

The paper titled The supervisory relationship in the doctoral process: how do Croatian IS students see it? written by Gordana Gašo, Martina Dragija Ivanović and Sanjica Faletar Tanacković presented results from the study conducted on the topic of LIS doctoral students' perceptions and experiences about the supervision during their doctoral study programs, with special emphasis on the qualities of good supervisors and doctoral students. Results showed that doctoral students tend to prefer formally regulated supervisory relationships because supervisors and students both have unambiguous and clear understanding of their roles and responsibilities. The findings also reveal that doctoral students seek support in the following areas: research, methodology, emotional support, and administrative procedures. The list of plausible characteristics of a good supervisor was also created in the study and it includes: having time for the student, providing students with timely and constructive feedback, setting research goals and timeline together and helping students become independent in scientific work.

Author Virginia M. Tucker presents an interesting study in the paper titled Becoming an information architect: The evolving librarian's skillset, mindset, and professional identity. She reports on research done via an online course Information architecture that was designed around the principles of threshold concepts, practical knowledge for the workplace, and professional 'soft' skills, such as collaboration and basic project management. Students on the course had the opportunity to collaborate with their peers to design content-rich and user-centred websites and they reported a shift in their thinking about their professional roles, in their identities relative to both the LIS and IA domains, and in what they anticipate for their future career opportunities.

The paper titled Studying adolescent information needs and information behavior in the context of making everyday life decisions: methodological approach, main concerns and lessons learned by Alica Kolarić and Ivanka Stričević focuses on methodological constraints of the research done within adolescent everyday life information behavior. This paper gives an overview of methodologies used in the selected studies from the past ten years. The main contribution of this paper is the list of lessons learned from reviewed studies that can serve as guidelines and could be applied while researching adolescent everyday life information behavior.

Another insightful paper reports on the topic that is not researched enough within LIS body of literature. In the paper titled How can libraries support dementia friendly communities? The study into perceptions and experiences of Croatian Public Librarians authors Sanjica Faletar Tanacković, Kornelija Petr Balog and Sanda Erdelez report that librarians have not generally been recognised as professionals caring for persons 
with dementia, but in spite of that, recent research indicates that public libraries can contribute to the development of dementia friendly communities by supporting social inclusion, self-efficacy and capacity building of persons with Alzheimer's disease (AD), and by providing support to their informal caregivers. This study provides conclusions driven from the results and reports how Croatian public libraries tailor their spaces, collections, programs, and services to enhance the everyday experience of persons with $\mathrm{AD}$ and their caregivers.

Finally, in the paper titled Mapping the evolution of topics published by Education for Information, Fidelia Ibekwe, Fernanda Bochi and Daniel Martínez-Ávila perform a chronological overview of the editorial policy of the journal Education for Information (EFI) over its three decades of existence using topic detection and text mining methods. They studied how topics of the papers progressed, following trends in information science education. The results showed that the EFI displayed a remarkable stability in its editorial policy over more than three decades. From 2018, when the journal appointed its third Editor in Chief, a shift towards more technologically oriented topics and to specialties from other fields are perceptible such as, for example, health information, data science and digital humanities.

We believe that these eight scholarly papers will produce new understandings of these relevant topics and invite further research, which will eventually result in the growing body of professional knowledge. 